\title{
Alterations in Endogenous Opioid Functional Measures in Chronic Back Pain
}

\author{
Ilkka K. Martikainen, ${ }^{1}$ Marta Peciña, ${ }^{1}$ Tiffany M. Love, ${ }^{1,2}$ Emily B. Nuechterlein, ${ }^{1,6}$ Chelsea M. Cummiford, ${ }^{1}$ \\ Carmen R. Green, ${ }^{3,4,7}$ Richard E. Harris, ${ }^{3}$ Christian S. Stohler, ${ }^{8}$ and Jon-Kar Zubieta ${ }^{1,2,5}$ \\ ${ }^{1}$ Molecular and Behavioral Neuroscience Institute, and Departments of ${ }^{2}$ Psychiatry, ${ }^{3}$ Anesthesiology, ${ }^{4}$ Obstetrics and Gynecology, and ${ }^{5}$ Radiology, \\ University of Michigan, Ann Arbor, Michigan 48109, ${ }^{\circ}$ Neuroscience Graduate Program, University of Michigan, Ann Arbor, Michigan 48104, ${ }^{7}$ Department \\ of Health Management and Policy, School of Public Health, University of Michigan, Ann Arbor, Michigan 48109, and ${ }^{8}$ School of Dentistry, University of \\ Maryland, Baltimore, Maryland 21201
}

The absence of consistent end organ abnormalities in many chronic pain syndromes has led to a search for maladaptive CNS mechanisms that may explain their clinical presentations and course. Here, we addressed the role of brain regional $\mu$-opioid receptor-mediated neurotransmission, one of the best recognized mechanisms of pain regulation, in chronic back pain in human subjects. We compared $\mu$-opioid receptor availability in vivo at baseline, during pain expectation, and with moderate levels of sustained pain in 16 patients with chronic nonspecific back pain (CNBP) and in 16 age- and gender-matched healthy control subjects, using the $\mu$-opioid receptor-selective radioligand $\left[{ }^{11} \mathrm{C}\right]$ carfentanil and positron emission tomography. We found that CNBP patients showed baseline increases in thalamic $\mu$-opioid receptor availability, contrary to a previously studied sample of patients diagnosed with fibromyalgia. During both pain expectation and sustained pain challenges, CNBP patients showed regional reductions in the capacity to activate this neurotransmitter system compared with their control sample, further associated with clinical pain and affective state ratings. Our results demonstrate heterogeneity in endogenous opioid system functional measures across pain conditions, and alterations in both receptor availability and endogenous opioid function in CNBP that are relevant to the clinical presentation of these patients and the effects of opioid analgesics on $\mu$-opioid receptors.

\section{Introduction}

Back pain is an exceedingly common condition affecting $70-$ $85 \%$ of all people during their lifetimes (Andersson, 1999). Most patients recover from an episode of acute back pain, but in a sizable number of individuals it persists or frequently recurs, leading to chronicity. In the majority of these patients no pathoanatomical diagnosis can be established, and, likely due to poor understanding of the cause of the pain, the treatment options for chronic nonspecific back pain (CNBP) have remained unsatisfying (Kuijpers et al., 2011; Balagué et al., 2012). The lack of apparent end organ pain generators raises the question of whether the pathogenesis of CNBP involves hyperalgesia maintained by pain-

Received April 2, 2013; revised July 30, 2013; accepted Aug. 3, 2013.

Author contributions: C.S.S. and J.-K.Z. designed research; E.B.N., C.M.C., C.R.G., and R.E.H. performed research; I.K.M., M.P., and T.M.L. analyzed data; I.K.M. and J.-K.Z. wrote the paper.

The study was supported by National Institute on Drug Abuse Grants R01 DA 022520 and R01 027494, and the Phil F. Jenkins Foundation. I.K.M. was supported by the Swedish Cultural Foundation in Finland, Helsinki, Finland. E.B.N. was in part supported by National Institutes of Health Grants NIH 5T32EY017878 and NIH 5T32DA007281. We thank nurse Kathleen Singer and Laurie Carr for patient screening and recruitment, and the nuclear medicine technologists at the Center for Positron Emission Tomography at the University of Michigan for the assistance in positron emission tomography data acquisition and reconstruction.

J.K.Z. has received compensation for consultation from Eli Lilly and Company, Johnson \& Johnson, and Abbott Laboratories within the 3 years prior to manuscript submission for work unrelated to the content of this manuscript. The authors declare no competing financial interests.

Correspondence should be addressed to Dr. Jon-Kar Zubieta, Molecular and Behavioral Neuroscience Institute, University of Michigan, 205 Zina Pitcher Place, Ann Arbor, MI 48109-0720. E-mail: zubieta@umich.edu.

DOI:10.1523/JNEUROSCI.1400-13.2013

Copyright $\odot 2013$ the authors $\quad 0270-6474 / 13 / 3314729-09 \$ 15.00 / 0$ related neuroplastic changes, otherwise primarily characterized at the level of primary sensory and dorsal horn neurons (Woolf and Salter, 2000). In patients with chronic back pain, the hypothesis of maladaptive CNS changes has received considerable support from recent imaging studies showing brain structural and functional alterations related to the individual pain characteristics (Apkarian et al., 2004; Baliki et al., 2011, 2012).

A large body of evidence demonstrates the central role of the brain $\mu$-opioid receptor (MOR) system in pain regulation ( $\mathrm{Zu}$ bieta, 2008). The significance of brain MORs in the endogenous regulation of acute pain in humans has been highlighted by positron emission tomography (PET) studies demonstrating $\mu$-opioid system activation during painful stimulation in multiple brain regions, including the periaqueductal gray, mid- and lateral thalamus, hypothalamus, nucleus accumbens, and amygdala, as well as in the insular, anterior cingulate, and prefrontal cortices (Zubieta et al., 2001, 2002; Bencherif et al., 2002). Consistent with its role in pain and stress suppression, pain-induced MOR activation was negatively correlated with the sensory and affective ratings of the pain experience, as well as with the negative affective state experienced during the challenge (Zubieta et al., 2001, 2002).

In patients with neuropathic pain, studies using the nonselective opioid receptor radioligand $\left[{ }^{11} \mathrm{C}\right]$ diprenorphine have shown reductions in baseline opioid receptor availability when compared with healthy control (HC) subjects (Jones et al., 2004; Willoch et al., 2004; Maarrawi et al., 2007). Similar reductions, albeit with a different regional involvement, have been found in fibro- 
Table 1. Demographic data of HC subjects and patients with CNBP and FM

\begin{tabular}{|c|c|c|c|c|}
\hline \multirow[b]{2}{*}{ Demographic data } & \multicolumn{2}{|l|}{ CNBP } & \multicolumn{2}{|l|}{ FM } \\
\hline & $\begin{array}{l}\text { Patients } \\
(N=16)\end{array}$ & $\begin{array}{l}\text { Control } \\
(N=16)\end{array}$ & $\begin{array}{l}\text { Patients } \\
(N=19)\end{array}$ & $\begin{array}{l}\text { Control } \\
(N=19)\end{array}$ \\
\hline \multicolumn{5}{|l|}{ Age (years) } \\
\hline Mean (SD) & $38(11)$ & $36(11)$ & $45(13)$ & $43(12)$ \\
\hline Range & $20-50$ & $20-49$ & $19-68$ & $20-61$ \\
\hline \multicolumn{4}{|l|}{ Race/ethnicity $[N(\%)]$} & $0 / 19$ \\
\hline African American & 0 & $1(6)$ & $1(5)$ & $1(5)$ \\
\hline Caucasian & $14(88)$ & $15(94)$ & $16(84)$ & $18(95)$ \\
\hline Hispanic & $1(6)$ & 0 & $2(11)$ & 0 \\
\hline Native American & $1(6)$ & 0 & 0 & 0 \\
\hline \multicolumn{5}{|l|}{ Pain duration (years) } \\
\hline Median (IQR) & $5.0(3.8)$ & & $4.0(6.5)$ & \\
\hline Range & $2-15$ & & $1-18$ & \\
\hline \multicolumn{5}{|l|}{ Pain intensity (VAS) } \\
\hline Mean (SD) & $49(20)$ & & 59 (17) & \\
\hline Range & $10-80$ & & $24-83$ & \\
\hline
\end{tabular}

Pain intensity was measured on a $0-100$ visual analog scale (VAS). IQR, Interquartile range.

myalgia (FM) using $\left[{ }^{11} \mathrm{C}\right]$ carfentanil (Harris et al., 2007). The reductions in opioid receptor availability in these chronic pain conditions have been interpreted as reflecting persistent endogenous opioid system activation and a downregulation of these receptor sites. Indeed, after successful treatment, recovery of opioid receptor availability has been shown in small samples of chronic pain patients in parallel with improvements in pain report (Jones et al., 1994, 1999).

Here, we examined whether CNBP is associated with dysfunctions in brain regional MOR neurotransmission, studied at baseline, during the expectation of pain, and during sustained, experimental muscle pain (Stohler and Kowalski, 1999). We hypothesized that alterations in brain MOR functional measures would be associated with clinical pain, affective state, and reductions in gray matter volume (Apkarian et al., 2004), as the latter may be related to deficits in pain regulatory mechanisms.

\section{Materials and Methods}

Subjects. We compared 16 CNBP patients [ 8 males and 8 females; mean $( \pm S D)$ age, $38 \pm 11$ years] with 16 age- and gender-matched $\mathrm{HC}$ subjects ( 8 males and 8 females; mean age, $36 \pm 11$ years). For baseline receptor measure comparisons with the CNBP sample, we also examined data from a previously studied sample of 19 patients with FM (all females; mean age, $45 \pm 13$ years) and a separate age- and gender-matched HC group (all females; mean age, $43 \pm 12$ years; Table 1 ).

The study participants were as follows: right-handed nonsmokers, who did not use alcohol $>10$ units per week), did not perform physical exercise $>1 \mathrm{~h} / \mathrm{d}$, and had no recreational drug use. The HC subjects had neither current somatic or psychiatric diseases nor a history of them, and were not taking any regular medications. All participants provided written informed consent before entering the study. The study protocol was in accordance with the Declaration of Helsinki, and was approved by the Institutional Review Board and the Radioactive Drug Research Committee.

The CNBP patients were recruited from a local pain clinic with the following main inclusion criteria: current average back or neck pain intensity between 3 and 8 on a $0-10$ verbal rating scale ( 0 representing no pain, 10 representing the greatest pain intensity imaginable) with pain duration of at least 1 year; no current or past opioid use within the past year; and no history of psychiatric disease (except for mild depressive symptoms).

The CNBP patients were classified as having nonspecific back or neck pain (i.e., patients with specific diagnoses, nonspinal etiology, or radicular symptoms were not included in the study). The pain was localized in the low back in four patients, in the neck in four patients, and in larger areas in the back and neck in the remaining eight patients. The most intense pain was localized in the low back in 10 of 16 patients. The CNBP patients were using several different kinds of analgesic medications, with the most common being acetaminophen and nonsteroidal antiinflammatory drugs (7 of 16 patients), muscle relaxants (3 of 16 patients), selective serotonin reuptake inhibitors (SSRIs) or serotoninnorepinephrine reuptake inhibitors (SNRIs; 3 of 16 patients), and gabapentin ( 3 of 16 patients).

The FM patients were part of a subject group that had previously participated in a PET study examining the effects of acupuncture on brain MOR availability (Harris et al., 2009). Seventeen of the 19 FM patients studied were part of our earlier study, for which baseline MOR nondisplaceable binding potential $\left(\mathrm{BP}_{\mathrm{ND}}\right)$ data were available (Harris et al., 2007). The patients with FM met the American College of Rheumatology 1990 diagnostic criteria for FM for a minimum of 1 year (Wolfe et al., 1990), with a continued presence of pain on at least $50 \%$ of days. The analgesic medications used by the FM patients were SSRIs and SNRIs, which were used by a total of 10 of 19 patients. As in the CNBP sample, the FM patients had not been exposed to opioids for at least a year.

Pain expectation and sustained pain challenges. Performed only in the CNBP sample and its control group, the challenges consisted of a pain expectation condition ( $0.9 \%$ isotonic saline, administered 5-25 min after the start of the scan) and a painful condition (5\% hypertonic saline, administered 45-65 min after the start of the scan). The participants were informed of these two conditions, but not of their order or laterality, allowing for the assessment of the effects of pain expectation. In the pain condition, a steady state of moderate muscle pain was maintained by the infusion of a small amount of $5 \%$ hypertonic saline into the relaxed left masseter muscle via a computer-controlled closed-loop system (Zhang et al., 1993; Stohler and Kowalski, 1999). This prolonged painful stimulation during the PET scan allows reliable determination of $\mathrm{MOR} \mathrm{BP}_{\mathrm{ND}}$ during the individual pain experience (Zubieta et al., 2001), while the feedback mechanism ensures that the pain experience is comparable across individual subjects and subject groups (Stohler and Kowalski, 1999). Moreover, because none of the volunteers had pain in the jaw or face area, choosing the masseter muscle for painful stimulation allowed for a better differentiation between experimental and clinical pain ratings, while at the same time introducing an increase in pain signal for the assessment of endogenous opioid system functional integrity.

The pain level was measured every $15 \mathrm{~s}$ by an electronic $0-100$ visual analog scale (VAS), representing "no pain" to "the highest pain intensity imaginable." Here, a computer-controlled pump injected an average volume of $2.4 \pm 1.0 \mathrm{ml}$ into the masseter muscle, with a target of $40 \mathrm{VAS}$ units; the actual average VAS rating in this study over the whole subject group was $31 \pm 13$ units. The isotonic saline solution was infused at the same rate as the hypertonic solution and was applied in the right masseter muscle, opposite to where pain was induced. In the data analysis, MOR activation during pain expectation and pain was defined as a reduction in MOR BP ${ }_{\mathrm{ND}}$ during the experimental condition when compared with the corresponding time frame in the baseline PET scan. The pain challenge was completed by all $\mathrm{HC}$ subjects $(N=16)$ and $15 \mathrm{CNBP}$ patients (i.e., one patient with CNBP did not complete the pain challenge).

At baseline and immediately after the isotonic and hypertonic saline infusions, the subjects completed the expanded form of the Positive and Negative Affect Schedule (PANAS; Watson and Clark, 1999) and the McGill Pain Questionnaire (MPQ; Melzack and Torgerson, 1971), which uses weighted word descriptors for the pain, and 0-100 VAS ratings of the pain intensity and unpleasantness. These measures, together with the average pain intensity ratings acquired every $15 \mathrm{~s}$ during the $20 \mathrm{~min}$ challenge, provided the measures of the individual pain experience during the challenges. Individual pain sensitivity was measured as the total volume of hypertonic saline solution (in milliliters) needed to keep the pain intensity in the target range.

Neuroimaging. The PET scans were acquired with a Siemens HR+ scanner in 3D mode with septa retracted and scatter correction [reconstructed full-width at half-maximum (FWHM) resolution, $5.5 \mathrm{~mm}$ inplane and $5.0 \mathrm{~mm}$ axially]. Each participant was positioned comfortably in the PET scanner gantry, and an intravenous (antecubital) line was placed in the right arm. A light forehead restraint was placed to eliminate head movement during the scan. $\left[{ }^{11} \mathrm{C}\right]$ carfentanil was synthesized at 
high specific activity by the reaction of $\left[{ }^{11} \mathrm{C}\right]$ methyliodide and a nonmethyl precursor, as described previously (Dannals et al., 1985; Jewett, 2001). An exposure of $15 \pm 1.0 \mathrm{mCi}(555 \pm 37 \mathrm{MBq})$ was administered during the scan, with a mass of carfentanil injected of $<0.05 \mu \mathrm{g} / \mathrm{kg}$ per scan. Fifty percent of the $\left[{ }^{11} \mathrm{C}\right]$ carfentanil dose was administered as a bolus, and the remaining $50 \%$ as a continuous infusion for the remainder of the study. Twenty-eight frames of images were acquired over $90 \mathrm{~min}$ with an increasing duration ( $30 \mathrm{~s}$ up to $10 \mathrm{~min}$ ). The HC subjects and CNBP patients underwent two 90 min PET scans with $\left[{ }^{11} \mathrm{C}\right]$ carfentanil, one scan without any intervention for baseline $\mathrm{MOR} \mathrm{BP}_{\mathrm{ND}}$ assessment, and another scan for the measurement of MOR activation during pain expectation and experimental pain. Scan order was randomized and counterbalanced. The FM patients and the corresponding HC subjects participated only in the baseline PET scan.

PET images were reconstructed using iterative algorithms (brain mode; Fourier rebinning with ordered subsets-expectation maximization, four iterations, 16 subsets; no smoothing) into a $128 \times 128$ pixel matrix in a $28.8-\mathrm{cm}$-diameter field of view. Attenuation correction was performed through a 6 min transmission scan $\left({ }^{68} \mathrm{Ge}\right.$ source $)$ obtained before the PET study, and with iterative reconstruction of the blank/ transmission data followed by segmentation of the attenuation image. Small head motions during emission scans were corrected by an automated computer algorithm for each subject before analysis, and the images were coregistered with the same software (Minoshima et al., 1993). After this, time points were decay corrected during reconstruction of the PET data.

Image data were transformed on a voxel-by-voxel basis into the following two sets of parametric maps: (1) a tracer transport measure $\left(K_{1}\right.$ ratio); and (2) a receptor-related measure (i.e., $\mathrm{BP}_{\mathrm{ND}}$ ). A modified Logan graphical analysis (Logan et al., 1996) was used to calculate the tracer transport and $\mathrm{BP}_{\mathrm{ND}}$, obviating the need for arterial blood sampling. The occipital cortex, an area devoid of MORs, was used as the reference region. The slope of the Logan plot was used for the estimation of the $\mathrm{BP}_{\mathrm{ND}}$, a measure equal to $f_{\mathrm{ND}} B_{\max } / K_{\mathrm{d}}$, where $B_{\max }$ represents the concentration of receptors and $K_{\mathrm{d}}$ their affinity for the radioligand, and the $\operatorname{term} f_{\mathrm{ND}}$ refers to the concentration of free radiotracer in the extracellular fluid, which is considered to represent a constant and very small value.

Anatomical T1-weighted magnetic resonance imaging (MRI) data were acquired on a 3 T scanner (Signa LX; General Electric), using 3D inversion recovery-prepared fast spoiled gradient recalled acquisition (echo time $=1.9 \mathrm{~ms}$; repetition time $=9.2 \mathrm{~ms}$; inversion time $=500 \mathrm{~ms}$; flip angle $=15^{\circ}$; bandwidth $=16 \mathrm{kHz}$; number of excitations $=1 ; 256 \times$ 256 matrix; field of view $=25 / 26 \mathrm{~cm}$; number of contiguous images $=$ 154; isotropic voxel size $=1 \mathrm{~mm}$ ).

$\mathrm{MR}, K_{1}$, and $\mathrm{BP}_{\mathrm{ND}}$ images were coregistered to each other and to the Montreal Neurological Institute (MNI) stereotactic atlas orientation using Statistical Parametric Mapping software (SPM8; Wellcome Trust Centre for Neuroimaging, London, UK; http://www.fil.ion.ucl.ac. $\mathrm{uk} / \mathrm{spm} /$ ) and Matlab (MathWorks). MOR binding maps were normalized with the deformation field obtained from the normalization of the MR images to the MNI atlas orientation using the VBM8 toolbox (http://dbm.neuro.uni-jena.de/vbm/). The accuracy of the coregistration and normalization algorithms was confirmed for each subject individually by comparing the transformed images to each other and to the MNI atlas template. Statistical parametric maps of group differences were generated with SPM8. No global normalization was applied to the data; therefore, the calculations presented are based on absolute $f_{\mathrm{ND}} B_{\max } / K_{\mathrm{d}}$ estimates. Only regions with specific MOR $\mathrm{BP}_{\mathrm{ND}}$ were included in the analyses (i.e., voxels with $\mathrm{BP}_{\mathrm{ND}}$ values $>0.1$ ). To compensate for small residual anatomic variations across subjects and to improve signal-to-noise ratios, a 6 mm FWHM Gaussian filter was applied to each scan.

MRI data processing for voxel-based morphometry (VBM) analysis was performed using VBM8 toolbox, with default parameters for image processing. This included bias regularization, and tissue classification and registration using linear (affine) and nonlinear transformations within a unified model (Ashburner and Friston, 2005). Highdimensional spatial normalization was made to the DARTEL template (Diffeomorphic Anatomical Registration using Exponentiated Lie algebra; Biomedical Image Analysis Group, Imperial College London, Lon- don, UK). The analysis was performed on the volume of gray matter, multiplied by the nonlinear, but not linear, components derived from the normalization matrix. This procedure preserves actual local gray matter volume, accounting for individual brain size (modulated gray matter volume). The realigned and normalized gray matter segments were smoothed with an $8 \mathrm{~mm}$ FWHM Gaussian kernel.

Data analysis. We examined the effects of CNBP and FM on baseline MOR $\mathrm{BP}_{\mathrm{ND}}$ by applying a general linear model (GLM) on a voxel-byvoxel basis using SPM8. The PET data from the FM sample were processed and reanalyzed by the same person in parallel with the PET data from the CNBP sample, using the same assumptions and tools. Instead of simply comparing the new data from the CNBP sample to the previously published data on FM (Harris et al., 2007), this approach accounted for differences in data-processing streams and updated software that might potentially affect the results. The effects of CNBP on pain expectation and pain-induced MOR activation (defined as a reduction in the MOR $\mathrm{BP}_{\mathrm{ND}}$ measure from baseline to nonpainful isotonic saline or painful hypertonic saline condition, respectively) were determined using a mixed-model ANOVA, with the diagnostic group (HC/CNBP) as the between-subject factor and the change in MOR $\mathrm{BP}_{\mathrm{ND}}$ as the withinsubject dependent variable. For all analyses, age was included as a nuisance covariate. For the pain challenges, we also included the average VAS pain ratings during the hypertonic saline infusion as a nuisance covariate to control for small differences between subjects. Significant effects were detected in the whole-brain voxel-by-voxel analysis using a statistical threshold that controls a type I error rate at $p<0.05$ (false discovery rate corrected for multiple comparisons). These statistical thresholds were estimated using the Euler characteristic (Worsley et al., 1992), based on the number of voxels in the gray matter, image smoothness, and the extent of local changes (correction for cluster volume; Friston et al., 1991). The numerical values for $\mathrm{MOR} \mathrm{BP}_{\mathrm{ND}}$ were extracted from the image data by averaging the values of voxels contained in the area in which significant effects were obtained in the analyses.

We compared the gray matter of $\mathrm{HC}$ subjects and CNBP patients using a whole-brain VBM analysis with VBM8, covarying for age. Voxels with gray matter value $<0.1$ were excluded from the analysis. We used a height threshold of $p<0.001$ (uncorrected) with an extent of 80 voxels ( 270 $\mathrm{mm}^{3}$; corresponding to the expected number of voxels per cluster) across the whole brain for searching significant differences in brain gray matter volume, with a priori hypothesis of regional reduction of brain gray matter as demonstrated by earlier studies (Apkarian et al., 2004; Seminowicz et al., 2011; Ivo et al., 2013). Additionally, the clusters showing significant alterations in endogenous opioid function in the CNBP sample were used to perform a region of interest (ROI)-based VBM analysis. A multivariate GLM was used to evaluate the group effects on gray matter volume, where the diagnostic group was included as an independent variable, regional gray matter volume as a dependent variable, and age as a covariate.

Before performing statistical tests, the distribution of each variable was tested and a parametric or nonparametric test was selected for further analysis accordingly. SPSS version 19 (SPSS) was used for assessing group differences and planned correlations between $\mathrm{MOR} \mathrm{BP}_{\mathrm{ND}}$, local gray matter volume and clinical measures. Statistical significance was set at $p<0.05$.

\section{Results}

\section{General characteristics of the patients and controls}

Demographic data of the CNBP and FM patients and the corresponding $\mathrm{HC}$ subjects are shown in Table 1. There were no significant differences between the patients with CNBP and FM in terms of pain duration $\left(U_{(33)}=150, Z=-0.03, p=0.99\right)$ or rating of current clinical pain intensity on a $0-100 \mathrm{VAS}\left(t_{(33)}=\right.$ $1.5, p=0.14)$. Average age was slightly higher in the FM than the CNBP group, but this difference was not statistically significant $\left(_{(33)}=1.8, p=0.08\right)$. 


\section{Baseline MOR $\mathrm{BP}_{\mathrm{ND}}$ in $\mathrm{CNBP}$ and controls}

The CNBP patients showed significant increases in baseline thalamic MOR $\mathrm{BP}_{\mathrm{ND}}$ compared with its control sample (Fig. 1), as follows: right thalamus, peak MNI coordinates $(x, y, z)$ at $(10,-12,6)$ : cluster size $=3070 \mathrm{~mm}^{3}, Z=5.1$, mean $\mathrm{MOR}$ $\mathrm{BP}_{\mathrm{ND}}$ increase of $18 \%$; left thalamus, peak MNI coordinates at $(-9,-9,4)$ : cluster size $=1630 \mathrm{~mm}^{3}, Z=4.1$, mean $\mathrm{MOR}$ $\mathrm{BP}_{\mathrm{ND}}$ increase of $23 \%$. No significant clusters were found in the opposite contrast $(\mathrm{HC}>\mathrm{CNBP})$.

Regional MOR $\mathrm{BP}_{\mathrm{ND}}$ in the CNBP group was negatively correlated with positive affect ratings, as measured with the PANAS, in both the right $(r=-0.56$, $p=0.03)$ and left thalamus $(r=-0.66$, $p=0.006$; Fig. $2 A, B)$. Negative affect (PANAS), duration of clinical pain, clinical pain ratings using VAS or MPQ total, and sensory and pain affect subscale scores were not significantly associated with changes in thalamic $\mathrm{MOR} \mathrm{BP}_{\mathrm{ND}}$ $(p>0.4)$.

To eliminate the possibility that the increases in MOR $\mathrm{BP}_{\mathrm{ND}}$ in CNBP patients, not previously observed in other persistent pain conditions, could be due to technical factors such as changes in image-processing streams, previously acquired baseline data in FM patients was also analyzed against a matched control group (Harris et al., 2007). Contrary to the CNBP sample, patients with FM exhibited significantly lower MOR BP ${ }_{\mathrm{ND}}$ than their matched $\mathrm{HC}$ sample in several brain areas. These included the thalamus bilaterally, with a peak in the right thalamus [peak MNI coordinates at $(10,-15$, $1)$ : cluster size $=3510 \mathrm{~mm}^{3}, Z=6.0$, mean $\mathrm{MOR} \mathrm{BP} \mathrm{ND}_{\mathrm{N}}$ reduction of $22 \%$ ], the nucleus accumbens bilaterally [right, $(14,16$, $-8)$ : cluster size $=2390 \mathrm{~mm}^{3}, Z=6.0,19 \%$ reduction; left, peak MNI coordinates at $(-10,10,-11)$ : cluster size $=1400 \mathrm{~mm}^{3}$, $Z=4.8,16 \%$ reduction], the left amygdala/left hippocampus [peak MNI coordinates at $(-26,-9,-24)$ : cluster size $=253$ $\mathrm{mm}^{3}, Z=4.8,24 \%$ reduction], and the left insula [peak MNI coordinates at $(-42,-3,1)$ : cluster size $=503 \mathrm{~mm}^{3}, Z=4.4$, $20 \%$ reduction; Fig. 3 ]. A small cluster was also found in the right amygdala, although it failed to reach significance after full correction for multiple comparisons $[p=0.09$; peak MNI coordinates at $(22,-6,-24)$ : cluster size $=68 \mathrm{~mm}^{3}, Z=4.4,20 \%$ reduction]. The opposite contrast $(\mathrm{HC}<\mathrm{FM})$ did not show any significant effects.

\section{Function of MOR-mediated neurotransmission in CNBP}

We also examined whether differences between the $\mathrm{HC}$ and CNBP groups would be observed for the capacity to activate endogenous opioid neurotransmission in response to pain expectation (pain is expected but not received) and experimental pain.

From the perspective of affective measures, there were no significant differences in affective state between $\mathrm{HC}$ and CNBP subjects, at baseline (PANAS positive: $F_{(1,29)}=0.03, p=0.87$; PANAS negative: $\left.F_{(1,29)}=1.8, p=0.19\right)$, during the expectation of pain (positive: $F_{(1,29)}=1.8, p=0.20$; negative: $F_{(1,29)}=2.0$, $p=0.16$ ), or during pain (positive: $F_{(1,29)}=1.0, p=0.32$; negative: $\left.F_{(1,29)}=1.8, p=0.19\right)$.

As would be expected with the use of the adaptive pain maintenance system used in the studies, no significant differences were observed between the HC subjects and CNBP patients in their average $0-100$ VAS ratings acquired every $15 \mathrm{~s}$ during the experimental pain challenge (HC: $29 \pm 8.4$; CNBP: $33 \pm 12 ; t_{(27)}=-0.96$, $p=0.35)$ or total MPQ score (HC: $23 \pm 12$; CNBP: $24 \pm 11 ; t_{(28)}=$ $-0.22, p=0.83)$, confirming a similar experiential state in both groups. The total amount of hypertonic saline needed to maintain the pain experience at target levels was, however, different: CNBP patients required significantly less hypertonic saline than $\mathrm{HC}$ subjects to maintain pain (average amount of hypertonic saline: $2.7 \pm$ $0.84 \mathrm{ml}$ for HC subjects; $1.8 \pm 0.92 \mathrm{ml}$ for CNBP patients; $t_{(25)}=2.6$, $p=0.02$ ), consistent with the presence of generalized hyperalgesia in the patient group.

A mixed-model ANOVA on a voxel-by-voxel basis revealed significant group $(\mathrm{HC} / \mathrm{CNBP}) \times$ condition (pain expectation/ pain) interactions. During the pain expectation condition, we detected a significant interaction in the left amygdala, whereby patients with CNBP demonstrated lower endogenous opioid system activation $\left(\Delta \mathrm{BP}_{\mathrm{ND}}\right)$ than $\mathrm{HC}$ subjects [peak MNI coordinates at $(-20,-6,-17)$ : cluster size $=560 \mathrm{~mm}^{3}, \mathrm{Z}=4.2$; Fig. $4 A, B]$. During experimental sustained muscle pain, we also found a significant interaction in the same area, again with lower MOR activation in CNBP patients, compared with HC subjects [peak MNI coordinates at $(-26,-13,-12)$ : cluster size $=446 \mathrm{~mm}^{3}, Z=4.6$; Fig. $\left.4 C\right]$. We did not detect significant group $\times$ condition interactions for the opposite contrasts $(\mathrm{HC}<\mathrm{CNBP})$. 
A

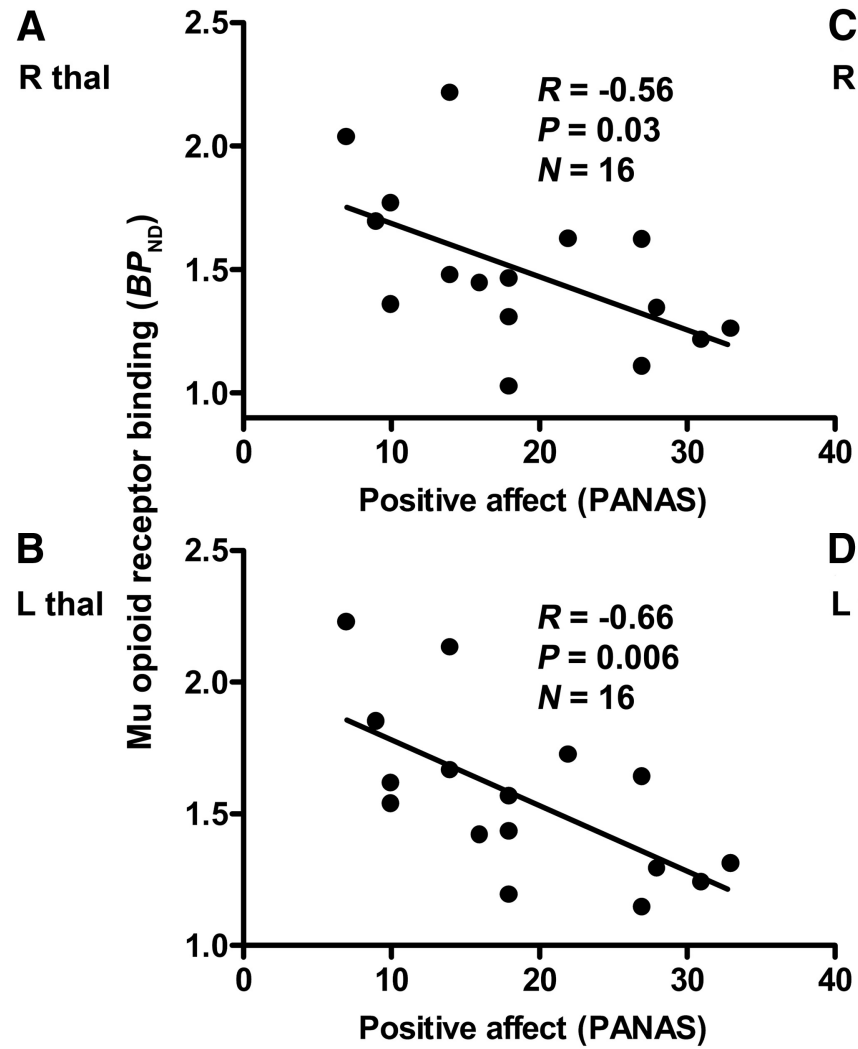

C

$\mathbf{R}$ thal

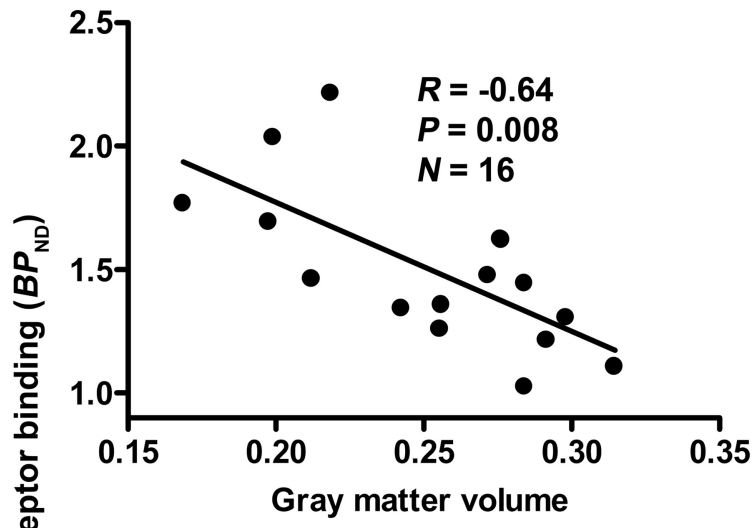

Figure 2. Associations between thalamic MORBP ${ }_{\mathrm{ND}}$ and positive affect and gray matter in CNBP patients. $\boldsymbol{A}, \boldsymbol{B}$, Significant negative correlations were found between $M O R \mathrm{RP}_{\mathrm{ND}}$ and positive affect as measured by PANAS in the right thalamus $(\mathrm{R}$ thal; $\boldsymbol{A})$ and left thalamus $(\mathrm{L}$ thal; $\boldsymbol{B})$. $\boldsymbol{C}, \boldsymbol{D}$, The thalamic MOR BP $\mathrm{ND}_{\mathrm{N}}$ was also negatively correlated with gray matter volume in the right $(\boldsymbol{C})$ and left thalamus $(\boldsymbol{D})$.

Because the increased thalamic MOR BP ${ }_{\mathrm{ND}}$ in CNBP at baseline may be related to a reduced endogenous opioid release in this region, we performed an additional mixed-model ANOVA that was spatially limited to the bilateral thalamic clusters showing increased MOR $\mathrm{BP}_{\mathrm{ND}}$ at baseline. This analysis found reduced MOR activation in the CNBP group in the thalamus, bilaterally, during the pain challenge, but not in the pain expectation condition [right thalamus, peak MNI coordinates at $(16,-24,3)$ : cluster size $=135 \mathrm{~mm}^{3}, Z=3.1$; left thalamus, peak MNI coordinates at $(-9,-7,0)$ : cluster size $\left.=672 \mathrm{~mm}^{3}, Z=3.4\right]$. No associations were found between the pain-induced MOR activation and baseline MOR BP ${ }_{\mathrm{ND}}$ in these clusters, although a trend toward significant negative correlation was observed in the left thalamus (right thalamus: $p=0.3$; left thalamus: $r=-0.33, p=0.07$ ). Again, no significant group $\times$ condition interactions were found for the opposite contrasts $(\mathrm{HC}<\mathrm{CNBP})$.

We then examined the relationships between the magnitude of MOR activation during the two experimental conditions and ratings of experimental and clinical pain, as well as affective state. The activation of MOR neurotransmission in CNBP patients in the left amygdala during pain expectation was positively correlated with PANAS positive affect ratings during that condition $(r=0.52, p=0.046)$. During the pain challenge, MOR system activation in the left amygdala was negatively correlated with back pain VAS intensity $(r=-0.59, p=0.02)$ and VAS unpleasantness scores $(r=-0.55, p=0.04)$, but not with back pain MPQ ratings or ratings of experimental pain $(p>0.2)$. Also, a positive correlation was observed between the magnitude of MOR activation and PANAS positive affect scores during the pain challenge $(r=0.54, p=0.04)$. No relationships were de- tected between the MOR activation in the thalamic clusters and VAS or MPQ pain ratings $(p>0.2)$ or PANAS positive and negative affect scores $(p>0.2)$. These data then indicate the presence of a deficit in endogenous opioid neurotransmission in the left amygdala that is related to the clinical presentation of these patients from both emotional and pain perspectives, observed in both pain expectation and experimental pain challenges.

\section{Voxel-based morphometry}

An examination of gray matter volumes in HC and CNBP volunteers was conducted to determine whether the alterations in measures of endogenous opioid function (increases in MOR availability in vivo and reductions in MOR activation during pain expectation or experimental pain challenge) would be associated with reductions in gray matter volume, as the latter has been reported in CNBP samples (Apkarian et al., 2004). Conversely, for small regions such as the thalamus or the amygdala, potential increases in gray matter volume could explain the increases in MOR availability observed in CNBP as an artifact of measurement, due to lesser partial volume-averaging effects with surrounding structures with low MOR availability such as white matter or CSF.

Global brain gray matter volumes did not differ between $\mathrm{HC}$ subjects and CNBP patients (HC: $631 \pm 75 \mathrm{ml}$; CNBP: $613 \pm 69$ $\left.\mathrm{ml} ; F_{(1,29)}=0.30, p=0.59\right)$. A VBM analysis showed significant regional reductions in gray matter volume in $\mathrm{CNBP}$, compared with HC subjects: left inferior frontal gyrus, peak MNI coordinates at $(-44,21,16)$ : cluster size $=527 \mathrm{~mm}^{3}, \mathrm{Z}=4.5$; medial aspect of the left superior frontal gyrus, peak MNI coordinates at 
$(-4,33,48)$ : cluster size $=1220 \mathrm{~mm}^{3}$, $\mathrm{Z}=4.0$; and lateral aspect of the left superior frontal gyrus, peak MNI coordinates at $(-14,18,49)$ : cluster size $=581 \mathrm{~mm}^{3}$, $Z=3.8$. In CNBP patients, gray matter volume in the left superior frontal gyrus $(-4,33,48)$ was negatively correlated with PANAS negative affect scores $(r=$ $-0.51, p=0.04)$. However, these prefrontal gray matter changes were not related to clinical pain ratings at the time of imaging $(p>0.2)$.

An ROI-based analysis was also used to compare gray matter volume in $\mathrm{HC}$ and CNBP samples for the regions where alterations in endogenous opioid mechanisms were observed. Significant gray matter loss was detected in the thalamus (right: HC, $0.29 \pm 0.04$; CNBP, $0.25 \pm$ $0.04 ; F_{(1,29)}=6.6, p=0.02$; left: HC, $0.27 \pm 0.03$; CNBP, $0.25 \pm 0.04 ; F_{(1,29)}=$ $4.8, p=0.04)$, but not in the left amygdala $(p>0.7)$. We found a significant negative correlation between gray matter volume and MOR BP ${ }_{\mathrm{ND}}$, but not MOR system activation during pain expectation or pain, in CNBP patients in both thalamic clusters (right: $r=-0.64, p=0.008$; left: $r=$ $-0.83, p<0.0001$; Fig. $2 C, D)$. The gray matter volume in these thalamic regions was also positively correlated with PANAS positive affect scores (right: $r=0.58, p=$ 0.02; left: $r=0.66, p=0.006)$, but not with clinical pain ratings $(p>0.2)$.

\section{Discussion}

We report regionally specific alterations in measures of MOR-mediated neurotransmission in CNBP. At baseline, patients with CNBP showed increases in MOR BP ${ }_{\mathrm{ND}}$ in the thalamus bilaterally when compared with $\mathrm{HC}$ subjects. These increases contrasted with reductions in regional $\mathrm{MOR} \mathrm{BP}_{\mathrm{ND}}$ in FM as well as reductions in overall opioid receptor availability reported in other forms of persistent pain (Jones et al., 2004; Willoch et al., 2004; Maarrawi et al., 2007). Baseline thalamic MOR BP $\mathrm{ND}_{\mathrm{ND}}$ in $\mathrm{CNBP}$ was negatively associated with gray matter volume in the same regions, and also negatively with positive affect.

In a second set of analyses, we examined the activation of endogenous opioid neurotransmission in response to pain expectation and sustained pain. An ROI approach was adopted for the thalamus, in the areas where increases in receptor availability were detected. We observed lower levels of thalamic MOR system activation during the pain challenge in CNBP in comparison with the HC group, suggesting that the upregulatory changes observed for baseline MOR $\mathrm{BP}_{\mathrm{ND}}$ are potentially secondary to a deficit in presynaptic endogenous opioid function in response to changes in pain signal. We also used a brain-wide, voxel-by-voxel comparison to compare the activation of the MOR system between the CNBP patients and the HC sample. During both experimental conditions, we found a significant group $\times$ condition interaction in the left amygdala, showing lower magnitudes of MOR system activation in the CNBP group with respect to the $\mathrm{HC}$ group. Consistent with the suppressive effect of MOR-mediated

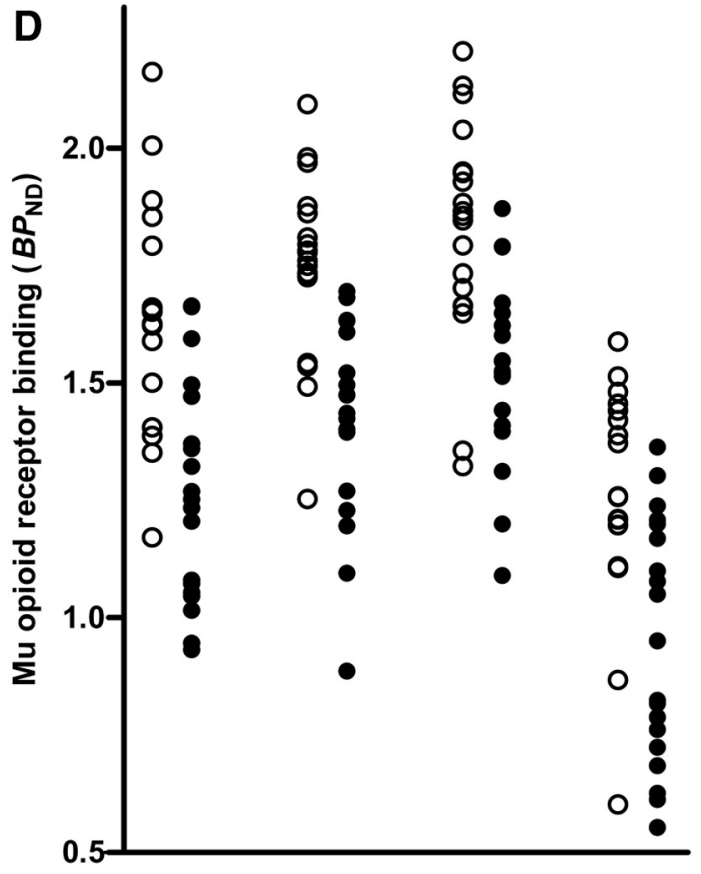

\section{$R$ thal $R$ nacc $L$ nacc $L$ amyl}

L hipp

Figure 3. Reductions in brain regional $M O R B P_{N D}$ in patients with $F M . A-C$, Significant reductions in $M O R B P_{N D}$, compared with accumbens ( $\mathrm{L}$ nacc; $Y=15 ; \boldsymbol{B}$ ), the left amygdala ( $\mathrm{L}$ amy)/left hippocampus ( $\mathrm{L}$ hipp; $Y=-9 ; \boldsymbol{C}$ ), and the left insula. $\boldsymbol{D}$, Plots of average cluster MOR BP ${ }_{\mathrm{ND}}$ values for $\mathrm{HC}$ subjects (empty circles, $N=19$ ) and FM patients (filled circles, $N=19$ ).

neurotransmission on pain but also affective regulation and stress responses, we showed that amygdala MOR activation during pain expectation was associated with the maintenance of positive affect during the challenge, while MOR activation in the same region during sustained pain was also negatively correlated with back pain ratings.

Significant alterations in MOR functional measures at baseline and during pain were found in the thalamus, a region with a critical role in conveying pain signals from the spinothalamic tract to higher-order cortical areas where pain is both represented and regulated. Reductions in blood flow to this region, as well as spontaneous neuronal hyperactivity have been reported in both patients and animal models of persistent neuropathic pain, suggesting reduced inhibitory neural activity (Guilbaud et al., 1990; Rinaldi et al., 1991; Iadarola et al., 1995; Paulson et al., 2002). In line with the hypothesis that reduced thalamic inhibition is present in persistent pain states, studies in patients with trigeminal neuropathy have found thalamic gray matter loss, dysregulated thalamocortical connectivity, and reduced concentrations of GABA, a major neurotransmitter mediating fast inhibition, in the thalamus (Gustin et al., 2011; Henderson et al., 2013). Although a considerable amount of severe chronic back pain may be neuropathic, at present it is not known whether these findings can be extended to CNBP (Schmidt et al., 2009). Nonetheless, our findings support the concept of reduced thalamic inhibition in chronic pain by showing that deficits in MOR activation may also lead to reduced inhibition of the pain signal and contribute to 


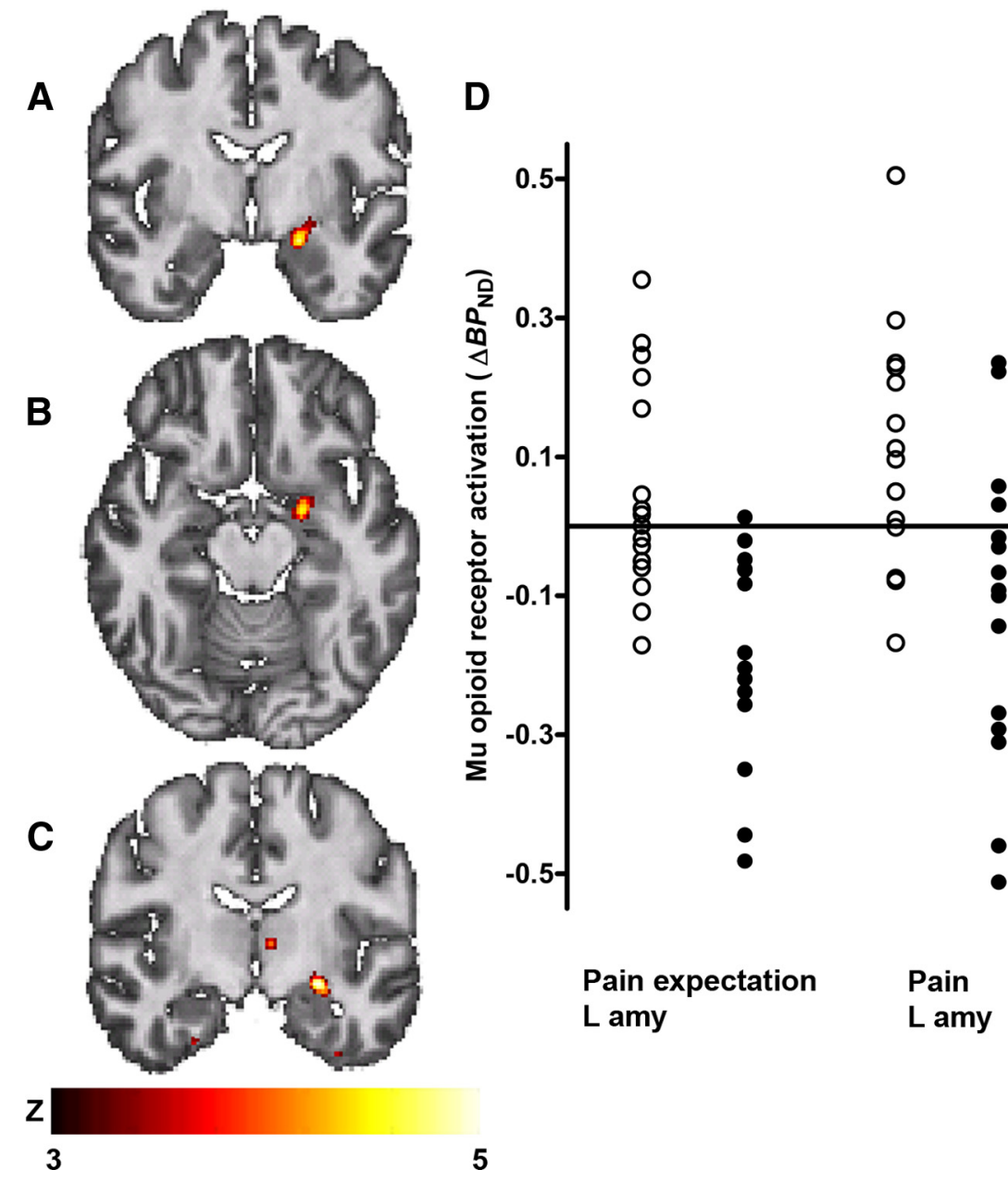

Figure 4. Differential effects of pain expectation and sustained experimental muscle pain on MORBP ${ }_{N D}$ in $H C$ subjects and CNBP patients. $A-C$, Significant differences in MOR activation were observed between HC and CNBP samples in the left amygdala (Lamy) during pain expectation, shown in coronal $(Y=-6 ; \boldsymbol{A})$ and axial planes $(Z=-15 ; \boldsymbol{B})$, and during sustained pain, shown in coronal plane $(Y=-12 ; \boldsymbol{C})$. D. Plots of average MOR BP ${ }_{\mathrm{ND}}$ changes for $\mathrm{HC}$ subjects (empty circles, $\left.N=16\right)$ and CNBP patients (filled circles, $N=15$ ).

enhanced pain, possibly by affecting pain-related thalamocortical circuitry (Carr and Bak, 1988; Brunton and Charpak, 1998; Baliki et al., 2011).

The amygdala, the region where reductions in endogenous opioid activity were observed during both pain expectation and experimental pain, has a central role in regulating emotional processes including acute and persistent pain (Neugebauer et al., 2004). Of the amygdala nuclei that participate in pain regulation, particularly the basolateral and lateral nuclei present high levels of MOR expression (Mansour et al., 1987), and these nuclei are also considered areas of interface and integration of multiple sensory inputs with emotional significance to the organism (Phelps and LeDoux, 2005). MOR receptor activation in this region has been shown to modulate descending inputs to the periaqueductal gray and rostral ventromedial medulla, reducing the magnitude of the pain signal (Helmstetter et al., 1998; McGaraughty and Heinricher, 2002). In healthy human subjects, the activation of endogenous MOR-mediated neurotransmission in the amygdala during sustained pain has been associated with reductions in pain intensity ratings (Zubieta et al., 2001). Here, we observe that deficits in the capacity to activate this neurotransmitter system during pain expectation and pain were associated with lower capacities to maintain positive affect, and with higher ratings of clinical pain intensity and its unpleasantness in CNBP patients. These findings are certainly consistent with the integrative and regulatory effects of the amygdala MORs on emotionally relevant sensory stimuli, including pain.

The regional deficits in MOR-mediated neurotransmission reported here are likely to participate in the amplification of the pain signal and in persisting back pain. These mechanisms may also lead to an increased sensitivity to experimental pain and to an increased risk of developing another chronic pain disorder, both features previously reported in CNBP and together implying dysfunctional pain control (Giesecke et al., 2004; Von Korff et al., 2005; O’Neill et al., 2007; Wiesinger et al., 2007). The hypothesis of dysfunctional endogenous opioid pain control in CNBP is supported by data showing low endogenous opioid concentrations in the CSF in chronic pain samples (Puig et al., 1982; Lipman et al., 1990), and an association between abnormal opioid system responses to naloxone, an opioid antagonist, and pain symptoms (Bruehl et al., 2004, 2010). At present, it is not possible to ascertain whether those deficits are secondary to the presence of persistent pain, or whether interindividual variations in the function of this neurotransmitter system represent a risk factor for the development of chronic back pain conditions, as has been suggested by other authors (Bruehl and Chung, 2006). Prospective studies after acute injury would be required to answer that particular question. Nevertheless, the data presented here demonstrate that endogenous opioid system markers do differ across persistent pain conditions and may represent a tool for the study of differences in the presentation and treatment response of varying forms of persistent pain. For example, reductions in the availability of opioid receptors in neuropathic pain and in FM have been suggested to underlie the poor response to opioid medications in those conditions (Jadad et al., 1992; Cherny et al., 1994; Dadabhoy and Clauw, 2006). In the case of CNBP, where mean increases in receptor availability were observed, however with substantial interindividual variability, opioid agonists are likely to induce varying levels of response, depending on receptor concentrations. The latter could contribute to a broader range of pain control efficacy by opioid medications, but also to individual variations in the physical dependence, rewarding, and tolerance effects of those drugs, which are also mediated by MORs (Sora et al., 1997).

The lower magnitudes of MOR-mediated neurotransmission observed in CNBP during both painful and nonpainful challenges may indicate the presence of reduced inhibition of nociceptive input, which in turn may lead to structural changes such as cortical reorganization (Flor et al., 1997) and gray matter loss in cortical and subcortical areas (Apkarian et al., 2004). Indeed, in the analyses of gray matter volume we were able to replicate the earlier finding of gray matter loss in the prefrontal cortex, which was correlated with negative affect (Apkarian et al., 2004; Ruscheweyh et al., 2011; Seminowicz et al., 2011; Ivo et al., 2013). 
We also found significant gray matter reductions in the bilateral thalamus, in accordance with some (Apkarian et al., 2004; Ivo et al., 2013), but not all previous studies in chronic back pain patients (Schmidt-Wilcke et al., 2006). Thalamic gray matter loss was correlated with increases, interpreted as compensatory, in MOR availability in the same region, while the amygdala, where reductions in endogenous opioid system function were substantial and detected in brain-wide analyses, heavily innervates prefrontal cortical regions (Porrino et al., 1981). This suggests that alterations in MOR neurotransmission may be contributing not only to the sensory and affective presentation of CNBP patients, but also to the neurodegenerative effects of persistent pain on brain gray matter. The contribution of the gray matter changes to pain chronification is yet to be determined due to mixed evidence as to whether these alterations are reversible or, at least partly, irreversible (Grachev et al., 2000; Rodriguez-Raecke et al., 2009; Gustin et al., 2011; Seminowicz et al., 2011).

The present report identifies alterations in what is arguably the main central antinociceptive system, the endogenous opioids and MORs, in patients with CNBP. These alterations were related to the sensory and affective elements of the pain experience, but also to the emotional state, all of which are thought to impact disability and the clinical course of persistent pain conditions. Perhaps more important from a diagnostic and therapeutic perspective, the directionality of the effects observed at the receptor availability level differed from those previously reported in other persistent pain conditions. Future studies appear warranted to further delineate differences across persistent pain states, given the relevance of these findings to the effects of opioid drugs, and potentially the complications associated with their administration, such as abuse and dependence. The possibility that interindividual variations in endogenous opioid system function may predispose individuals to the development of persistent pain after acute injury would also require further exploration.

\section{References}

Andersson GB (1999) Epidemiological features of chronic low-back pain. Lancet 354:581-585. CrossRef Medline

Apkarian AV, Sosa Y, Sonty S, Levy RM, Harden RN, Parrish TB, Gitelman DR (2004) Chronic back pain is associated with decreased prefrontal and thalamic gray matter density. J Neurosci 24:10410-10415. CrossRef Medline

Ashburner J, Friston KJ (2005) Unified segmentation. Neuroimage 26:839851. CrossRef Medline

Balagué F, Mannion AF, Pellisé F, Cedraschi C (2012) Non-specific low back pain. Lancet 379:482-491. CrossRef Medline

Baliki MN, Baria AT, Apkarian AV (2011) The cortical rhythms of chronic back pain. J Neurosci 31:13981-13990. CrossRef Medline

Baliki MN, Petre B, Torbey S, Herrmann KM, Huang L, Schnitzer TJ, Fields HL, Apkarian AV (2012) Corticostriatal functional connectivity predicts transition to chronic back pain. Nat Neurosci 15:1117-1119. CrossRef Medline

Bencherif B, Fuchs PN, Sheth R, Dannals RF, Campbell JN, Frost JJ (2002) Pain activation of human supraspinal opioid pathways as demonstrated by $[11 \mathrm{C}]$-carfentanil and positron emission tomography (PET). Pain 99: 589-598. CrossRef Medline

Bruehl S, Chung OY (2006) Parental history of chronic pain may be associated with impairments in endogenous opioid analgesic systems. Pain 124: 287-294. CrossRef Medline

Bruehl S, Chung OY, Ward P, Johnson B (2004) Endogenous opioids and chronic pain intensity: interactions with level of disability. Clin J Pain 20:283-292. CrossRef Medline

Bruehl S, Chung OY, Chont M (2010) Chronic pain-related changes in endogenous opioid analgesia: a case report. Pain 148:167-171. CrossRef Medline

Brunton J, Charpak S (1998) $\mu$-Opioid peptides inhibit thalamic neurons. J Neurosci 18:1671-1678. Medline
Carr KD, Bak TH (1988) Medial thalamic injection of opioid agonists: muagonist increases while kappa-agonist decreases stimulus thresholds for pain and reward. Brain Res 441:173-184. CrossRef Medline

Cherny NI, Thaler HT, Friedlander-Klar H, Lapin J, Foley KM, Houde R, Portenoy RK (1994) Opioid responsiveness of cancer pain syndromes caused by neuropathic or nociceptive mechanisms: a combined analysis of controlled, single-dose studies. Neurology 44:857-861. CrossRef Medline

Dadabhoy D, Clauw DJ (2006) Therapy insight: fibromyalgia-a different type of pain needing a different type of treatment. Nat Clin Pract Rheumatol 2:364-372. CrossRef Medline

Dannals RF, Ravert HT, Frost JJ, Wilson AA, Burns HD, Wagner HN Jr (1985) Radiosynthesis of an opiate receptor binding radiotracer: [11C]carfentanil. Int J Appl Radiat Isot 36:303-306. CrossRef Medline

Flor H, Braun C, Elbert T, Birbaumer N (1997) Extensive reorganization of primary somatosensory cortex in chronic back pain patients. Neurosci Lett 224:5-8. CrossRef Medline

Friston KJ, Frith CD, Liddle PF, Frackowiak RS (1991) Comparing functional (PET) images: the assessment of significant change. J Cereb Blood Flow Metab 11:690-699. CrossRef Medline

Giesecke T, Gracely RH, Grant MA, Nachemson A, Petzke F, Williams DA, Clauw DJ (2004) Evidence of augmented central pain processing in idiopathic chronic low back pain. Arthritis Rheum 50:613-623. CrossRef Medline

Grachev ID, Fredrickson BE, Apkarian AV (2000) Abnormal brain chemistry in chronic back pain: an in vivo proton magnetic resonance spectroscopy study. Pain 89:7-18. CrossRef Medline

Guilbaud G, Benoist JM, Jazat F, Gautron M (1990) Neuronal responsiveness in the ventrobasal thalamic complex of rats with an experimental peripheral mononeuropathy. J Neurophysiol 64:1537-1554. Medline

Gustin SM, Peck CC, Wilcox SL, Nash PG, Murray GM, Henderson LA (2011) Different pain, different brain: thalamic anatomy in neuropathic and non-neuropathic chronic pain syndromes. J Neurosci 31:5956-5964. CrossRef Medline

Harris RE, Clauw DJ, Scott DJ, McLean SA, Gracely RH, Zubieta JK (2007) Decreased central $\mu$-opioid receptor availability in fibromyalgia. J Neurosci 27:10000-10006. CrossRef Medline

Harris RE, Zubieta JK, Scott DJ, Napadow V, Gracely RH, Clauw DJ (2009) Traditional Chinese acupuncture and placebo (sham) acupuncture are differentiated by their effects on mu-opioid receptors (MORs). Neuroimage 47:1077-1085. CrossRef Medline

Helmstetter FJ, Tershner SA, Poore LH, Bellgowan PS (1998) Antinociception following opioid stimulation of the basolateral amygdala is expressed through the periaqueductal gray and rostral ventromedial medulla. Brain Res 779:104-118. CrossRef Medline

Henderson LA, Peck CC, Petersen ET, Rae CD, Youssef AM, Reeves JM, Wilcox SL, Akhter R, Murray GM, Gustin SM (2013) Chronic pain: lost inhibition? J Neurosci 33:7574-7582. CrossRef Medline

Iadarola MJ, Max MB, Berman KF, Byas-Smith MG, Coghill RC, Gracely RH, Bennett GJ (1995) Unilateral decrease in thalamic activity observed with positron emission tomography in patients with chronic neuropathic pain. Pain 63:55-64. CrossRef Medline

Ivo R, Nicklas A, Dargel J, Sobottke R, Delank KS, Eysel P, Weber B (2013) Brain structural and psychometric alterations in chronic low back pain. Eur Spine J. Advance online publication. Retrieved August 7, 2013. doi: 10.1007/s00586-013-2692-x. CrossRef Medline

Jadad AR, Carroll D, Glynn CJ, Moore RA, McQuay HJ (1992) Morphine responsiveness of chronic pain: double-blind randomised crossover study with patient-controlled analgesia. Lancet 339:1367-1371. CrossRef Medline

Jewett DM (2001) A simple synthesis of [11C]carfentanil using an extraction disk instead of HPLC. Nucl Med Biol 28:733-734. CrossRef Medline

Jones AK, Cunningham VJ, Ha-Kawa S, Fujiwara T, Luthra SK, Silva S, Derbyshire S, Jones T (1994) Changes in central opioid receptor binding in relation to inflammation and pain in patients with rheumatoid arthritis. Br J Rheumatol 33:909-916. CrossRef Medline

Jones AK, Kitchen ND, Watabe H, Cunningham VJ, Jones T, Luthra SK, Thomas DG (1999) Measurement of changes in opioid receptor binding in vivo during trigeminal neuralgic pain using [11C] diprenorphine and positron emission tomography. J Cereb Blood Flow Metab 19:803-808. Medline

Jones AK, Watabe H, Cunningham VJ, Jones T (2004) Cerebral decreases in 
opioid receptor binding in patients with central neuropathic pain measured by [11C]diprenorphine binding and PET. Eur J Pain 8:479-485. CrossRef Medline

Kuijpers T, van Middelkoop M, Rubinstein SM, Ostelo R, Verhagen A, Koes BW, van Tulder MW (2011) A systematic review on the effectiveness of pharmacological interventions for chronic non-specific low-back pain. Eur Spine J 20:40-50. CrossRef Medline

Lipman JJ, Miller BE, Mays KS, Miller MN, North WC, Byrne WL (1990) Peak B endorphin concentration in cerebrospinal fluid: reduced in chronic pain patients and increased during the placebo response. Psychopharmacology (Berl) 102:112-116. CrossRef Medline

Logan J, Fowler JS, Volkow ND, Wang GJ, Ding YS, Alexoff DL (1996) Distribution volume ratios without blood sampling from graphical analysis of PET data. J Cereb Blood Flow Metab 16:834-840. Medline

Maarrawi J, Peyron R, Mertens P, Costes N, Magnin M, Sindou M, Laurent B, Garcia-Larrea L (2007) Differential brain opioid receptor availability in central and peripheral neuropathic pain. Pain 127:183-194. CrossRef Medline

Mansour A, Khachaturian H, Lewis ME, Akil H, Watson SJ (1987) Autoradiographic differentiation of $\mu, \delta$, and $\kappa$ opioid receptors in the rat forebrain and midbrain. J Neurosci 7:2445-2464. Medline

McGaraughty S, Heinricher MM (2002) Microinjection of morphine into various amygdaloid nuclei differentially affects nociceptive responsiveness and RVM neuronal activity. Pain 96:153-162. CrossRef Medline

Melzack R, Torgerson WS (1971) On the language of pain. Anesthesiology 34:50-59. CrossRef Medline

Minoshima S, Koeppe RA, Mintun MA, Berger KL, Taylor SF, Frey KA, Kuhl DE (1993) Automated detection of the intercommissural line for stereotactic localization of functional brain images. J Nucl Med 34:322-329. Medline

Neugebauer V, Li W, Bird GC, Han JS (2004) The amygdala and persistent pain. Neuroscientist 10:221-234. CrossRef Medline

O’Neill S, Manniche C, Graven-Nielsen T, Arendt-Nielsen L (2007) Generalized deep-tissue hyperalgesia in patients with chronic low-back pain. Eur J Pain 11:415-420. CrossRef Medline

Paulson PE, Casey KL, Morrow TJ (2002) Long-term changes in behavior and regional cerebral blood flow associated with painful peripheral mononeuropathy in the rat. Pain 95:31-40. CrossRef Medline

Phelps EA, LeDoux JE (2005) Contributions of the amygdala to emotion processing: from animal models to human behavior. Neuron 48:175-187. CrossRef Medline

Porrino LJ, Crane AM, Goldman-Rakic PS (1981) Direct and indirect pathways from the amygdala to the frontal lobe in rhesus monkeys. J Comp Neurol 198:121-136. CrossRef Medline

Puig MM, Laorden ML, Miralles FS, Olaso MJ (1982) Endorphin levels in cerebrospinal fluid of patients with postoperative and chronic pain. Anesthesiology 57:1-4. CrossRef Medline

Rinaldi PC, Young RF, Albe-Fessard D, Chodakiewitz J (1991) Spontaneous neuronal hyperactivity in the medial and intralaminar thalamic nuclei of patients with deafferentation pain. J Neurosurg 74:415-421. CrossRef Medline

Rodriguez-Raecke R, Niemeier A, Ihle K, Ruether W, May A (2009) Brain gray matter decrease in chronic pain is the consequence and not the cause of pain. J Neurosci 29:13746-13750. CrossRef Medline

Ruscheweyh R, Deppe M, Lohmann H, Stehling C, Flöel A, Ringelstein EB, Knecht S (2011) Pain is associated with regional grey matter reduction in the general population. Pain 152:904-911. CrossRef Medline
Schmidt CO, Schweikert B, Wenig CM, Schmidt U, Gockel U, Freynhagen R, Tölle TR, Baron R, Kohlmann T (2009) Modelling the prevalence and cost of back pain with neuropathic components in the general population. Eur J Pain 13:1030-1035. CrossRef Medline

Schmidt-Wilcke T, Leinisch E, Gänssbauer S, Draganski B, Bogdahn U, Altmeppen J, May A (2006) Affective components and intensity of pain correlate with structural differences in gray matter in chronic back pain patients. Pain 125:89-97. CrossRef Medline

Seminowicz DA, Wideman TH, Naso L, Hatami-Khoroushahi Z, Fallatah S, Ware MA, Jarzem P, Bushnell MC, Shir Y, Ouellet JA, Stone LS (2011) Effective treatment of chronic low back pain in humans reverses abnormal brain anatomy and function. J Neurosci 31:7540-7550. CrossRef Medline

Sora I, Takahashi N, Funada M, Ujike H, Revay RS, Donovan DM, Miner LL, Uhl GR (1997) Opiate receptor knockout mice define mu receptor roles in endogenous nociceptive responses and morphine-induced analgesia. Proc Natl Acad Sci U S A 94:1544-1549. CrossRef Medline

Stohler CS, Kowalski CJ (1999) Spatial and temporal summation of sensory and affective dimensions of deep somatic pain. Pain 79:165-173. CrossRef Medline

Von Korff M, Crane P, Lane M, Miglioretti DL, Simon G, Saunders K, Stang P, Brandenburg N, Kessler R (2005) Chronic spinal pain and physicalmental comorbidity in the United States: results from the national comorbidity survey replication. Pain 113:331-339. CrossRef Medline

Watson D, Clark LA (1999) Manual for the positive and negative affect schedule- expanded form. Iowa City, IA: University of Iowa.

Wiesinger B, Malker H, Englund E, Wänman A (2007) Back pain in relation to musculoskeletal disorders in the jaw-face: a matched case-control study. Pain 131:311-319. CrossRef Medline

Willoch F, Schindler F, Wester HJ, Empl M, Straube A, Schwaiger M, Conrad B, Tölle TR (2004) Central poststroke pain and reduced opioid receptor binding within pain processing circuitries: a [11C]diprenorphine PET study. Pain 108:213-220. CrossRef Medline

Wolfe F, Smythe HA, Yunus MB, Bennett RM, Bombardier C, Goldenberg DL, Tugwell P, Campbell SM, Abeles M, Clark P (1990) The American College of Rheumatology 1990 criteria for the classification of fibromyalgia. Report of the Multicenter Criteria Committee. Arthritis Rheum 33: 160-172. CrossRef Medline

Woolf CJ, Salter MW (2000) Neuronal plasticity: increasing the gain in pain. Science 288:1765-1769. CrossRef Medline

Worsley KJ, Evans AC, Marrett S, Neelin P (1992) A three-dimensional statistical analysis for $\mathrm{CBF}$ activation studies in human brain. J Cereb Blood Flow Metab 12:900-918. CrossRef Medline

Zhang X, Ashton-Miller JA, Stohler CS (1993) A closed-loop system for maintaining constant experimental muscle pain in man. IEEE Trans Biomed Eng 40:344-352. CrossRef Medline

Zubieta JK (2008) Forebrain opiates. In: Science of pain, Ed 1 (Basbaum A, Bushnell MC, ed), pp 821-831. Amsterdam: Academic.

Zubieta JK, Smith YR, Bueller JA, Xu Y, Kilbourn MR, Jewett DM, Meyer CR, Koeppe RA, Stohler CS (2001) Regional mu opioid receptor regulation of sensory and affective dimensions of pain. Science 293:311-315. CrossRef Medline

Zubieta JK, Smith YR, Bueller JA, Xu Y, Kilbourn MR, Jewett DM, Meyer CR, Koeppe RA, Stohler CS (2002) $\mu$-Opioid receptor-mediated antinociceptive responses differ in men and women. J Neurosci 22:5100-5107. Medline 